\title{
Syntenin overexpression in human lung cancer tissue and serum is associated with poor prognosis
}

\author{
Pengyong Luo, Xuli Yang, Shiren Huang, Shu Feng and Zongxing Ou*
}

\begin{abstract}
Background: Lung cancer is the major malignant tumour. The present study was conducted to determine the expression level of syntenin in lung cancer tissues and serum from lung cancer patients and to explore its clinical significance.

Methods: Syntenin expression levels were determined in paraffin-embedded lung cancer tissue specimens $(n=191)$ using immunohistochemistry. The mRNA expressions of syntenin in fresh lung cancer tissues and the paracancerous tissues were examined by RT-qPCR $(n=25)$. Syntenin and VEGF expression levels were measured in serum from patients with lung cancer $(n=60)$ and control subjects $(n=30)$ using ELISA. The associations between syntenin and the clinicopathological features or prognosis in 191 patients with lung cancer were analysed. The correlation between the syntenin and VEGF levels in serum from 60 lung cancer patients was analysed.
\end{abstract}

Results: The expression levels of syntenin were significantly higher in lung cancer tissues than in paracancerous tissues based on immunohistochemistry and RT-qPCR, and elevated syntenin expression was significantly associated with tumour size $(P=0.002)$, TNM stage $(P=0.020)$, tumour distant metastasis $(P=0.033)$, overall survival $(\mathrm{OS})(P=0.002)$ and progression-free survival (PFS) $(P=0.001)$. Multivariate analysis revealed that increased expression of syntenin was an independent risk factor for OS $(P=0.006)$ and PFS $(P<0.001)$ in lung cancer patients. The expression levels of syntenin and VEGF in serum from lung cancer patients were higher than those from control subjects $(P<0.001, P<0.001$, respectively), and their expression levels were positively correlated $(r=0.49, P<0.001)$.

Conclusions: Syntenin expression is upregulated in lung cancer patients, and its serum expression level is positively correlated with VEGF. Moreover, syntenin overexpression was correlated with poor prognosis in patients with lung cancer.

Keywords: Syntenin, VEGF, Lung cancer, Expression, Prognosis

\section{Background}

The global morbidity and mortality due to malignant lung cancer is ranked the first [1], which seriously threatens human health and safety. Tumour invasion and metastasis are considered to be the main causes of treatment failure $[2,3]$. At present, lung cancer is mainly treated with surgery supplemented with radiotherapy, chemotherapy, targeted therapy and immunotherapy. However, due to metastasis and drug resistance, the

\footnotetext{
*Correspondence: zongxing0912@163.com

Department of Respiratory Medicine, Haikou Hospital Affiliated to Xiangya

Medical College, Central South University, 43 People's Avenue, Haikou 570208, Hainan, China
}

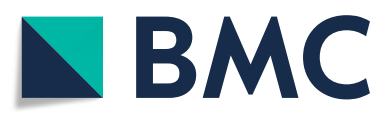

(c) The Author(s). 2020 Open Access This article is distributed under the terms of the Creative Commons Attribution 4.0 International License (http://creativecommons.org/licenses/by/4.0/), which permits unrestricted use, distribution, and

reproduction in any medium, provided you give appropriate credit to the original author(s) and the source, provide a link to the Creative Commons license, and indicate if changes were made. The Creative Commons Public Domain Dedication waiver (http://creativecommons.org/publicdomain/zero/1.0/) applies to the data made available in this article, unless otherwise stated. and improved treatment strategies are being sought continuously.

Although targeted molecular drugs improve the therapeutic effect of lung cancer, they are largely limited to patients with specific gene mutations. Angiogenesis is the formation of new blood vessels from the existing vascular network, which is more attractive and common in the development of targeted therapy [4]. In the firstline and second-line treatments, VEGF bevacizumab or VEGF receptor (VEGFR) ramolumab alone or in combination with chemotherapy prolong the total survival period [5]. While targeted management of angiogenesis 
is effective, there are too many potential signal pathways for angiogenesis, and the high heterogeneity of tumor may cause difficulties in clinical benefits of anti angiogenic therapy [6, 7]. Furthermore, at present, there are only few targeted drug for angiogenesis. At the same time, the resistance of drug targeting anti-angiogenesis is a serious issue, and it is necessary to find new therapeutic targets.

Syntenin, the melanoma differentiation-associated gene-9 (MDA-9), is involved in multiple signal cascades in the physiological and pathological processes of cells [8-10]. The roles of syntenin in tumour migration and invasion have been intensively investigated. The results showed that Syntenin binds to kinases or receptors on the cytoplasmic membrane to activate the P38/NF-kB, ERK1/2 pathways, AKT pathways, P38/MAPK, leading to progression and metastasis in various malignant tumours, such as melanoma, glioma, breast cancer, small cell lung cancer and liver cancer [11-15]. It is shown that the up-regulation of syntenin promotes the migration of non-metastatic cancer cells [16], and knockdown of syntenin inhibits the migration and invasion of cells $[17,18]$. In addition, syntenin has been shown to promote the formation of blood vessels [19]. VEGF has been demonstrated to be an important physiological and pathological factor for angiogenesis and play an important role in the occurrence and development of tumor [20]. By binding with VEGFR, it activates the tyrosinase activity of VEGFR, leading to proliferation of vascular endothelium and angiogenesis via the signal transduction [21]. Therefore, syntenin plays a vital role in the metastasis and progression of tumour.

At present, the roles of syntenin in lung cancer are still largely unclear, and there are few reports on the expression of syntenin in lung cancer tissues and its clinical significance. Therefore, the present study was performed to explore the associations between the expression of syntenin in patients with lung cancer and their clinicopathological characteristics and prognosis, and to analyze the expression level of serum syntenin and its correlation with VEGF expression level in patients with lung cancer. The findings would lay the foundation for further investigation of new diagnostic and prognostic markers of lung cancer and new therapeutic targets.

\section{Methods}

\section{Patients, tissue and serum sample}

From the database of patients who were diagnosed with primary lung cancer by pathological examination at Haikou Hospital between 2012 and 2014, 191 lung cancer patients were included with sample size determined based on previous described method [22], including 140 men and 51 women who were aged from 27 to 89 years old. Paraffin tissues from the 191 lung cancer patients and 80 samples of lung tissue adjacent to tumours from the matched group were obtained from the pathology department of Haikou Hospital. Eighty samples of paraffin-embedded lung tissues were obtained from 80 cases of surgical treatment among the 191 patients. These samples were used for determining the expression of syntenin in the lung cancer and paracancerous normal tissues. Patients for immunohistochemistry study were included if their lung cancer was confirmed by pathological biopsy with complete clinical data complete clinical data on gender, age, tumor size, lymph node metastasis and distant metastasis, tumor pathological data, performance status score and treatments. They were followed-up till death of the end of this study with minimal survival time of 1 month. No patient was lost during the study. From June 2019 to August 2019, 25 cases of lung cancer patients with fresh lung cancer tissues and their paracancerous normal lung tissues were used for qPCR analysis. The paracancerous tissue adjacent to cancer was more than $3 \mathrm{~cm}$ from the edge of cancer, and all the samples were confirmed by pathological examinations.

The venous blood was extracted from sixty lung cancer patients for analysing serum syntenin and VEGF levels. These patients were diagnosed by pathological biopsy for the first time in the Department of Respiratory Medicine at Haikou Hospital between October 2018 and April 2019, including 41 men and 19 women aged 43 to 79 years old and not subject to anticancer treatment before diagnosis. Thirty volunteers who received physical examinations at the Haikou Hospital were enrolled as the control group. Venous blood was collected in the morning, and the serum was separated after centrifugation and stored at $-20^{\circ} \mathrm{C}$. The lung cancer group and the control group had no significant differences in age, gender and living area.

The exclusion criteria included the presence of other serious acute and chronic diseases, such as severe COPD, cerebral haemorrhage, cerebral infarction, myocardial infarction, hypertension, diabetes, liver cirrhosis, uraemia, sepsis, MODS or combined tumour type, or acute trauma.

\section{Treatment and follow-up}

Among the 191 patients included, 80 received surgical treatment, 76 of them were at stage I, II and resectable stage IIIA, and they underwent segmental or lobectomy plus lymphadenectomy, and 4 of them received palliative lobectomy and other systemic treatment. 111 cases were treated with individualized conservative chemotherapy based on the tumor stage, PS (Performance status) score and patients' economic situation. 34 of them received EGFR TKI inhibitor gefitinib as the first-line treatment, the rest received platinum chemotherapy and palliative 
symptomatic supportive treatment. All patients were followed up every 3 month for one to 84 months. The OS was calculated from the diagnosis of lung cancer to the end of follow-up or the patient's death, and the PFS was calculated from when the patient first received treatment until the first disease progression or the patient's death. After treatment, patients were evaluated for progress of tumor with chest CT, head MRI, abdomen CT and whole body bone scan.

\section{Immunohistochemistry}

Tissue sections $(3 \mu \mathrm{m})$ were routinely dewaxed, hydrated and heated to retrieve the antigens. Endogenous peroxidase activity was suppressed with $3 \% \mathrm{H}_{2} \mathrm{O}_{2}$ for $20 \mathrm{~min}$ at $25^{\circ} \mathrm{C}$. To suppress nonspecific binding of antibody, the tissue sections were immersed in $10 \%$ goat serum for $20 \mathrm{~min}$. The slides were incubated with a monoclonal antibody against syntenin (Abcam 133,267, Cambridge, UK, dilution 1:150) overnight at $4{ }^{\circ} \mathrm{C}$. After intensive rinsing in PBS, the slides were incubated with biotinlabelled secondary antibody (MXB Biotechnology, Fuzhou, China) for $15 \mathrm{~min}$ at $25^{\circ} \mathrm{C}$. The staining was developed with diaminobenzidine (MXB Biotechnology, Fuzhou, China), and counterstained with haematoxylin, dehydrated and mounted for microscopy. The primary antibody was omitted in the negative control.

The stained sections were reviewed independently by two pathologists who were blinded to the clinical outcomes, and 10 high-magnification microscopic fields were randomly selected for each treatment. The immunoreactive score (IR) [23] was used to calculate immunoreactivity and was calculated as IRS = SI (staining intensity) "PP (percentage of highly-expressing cells). The SI was defined as follows: 0 , negative; 1 , low; 2 , medium; 3 , high. The PP was scored as follows: $0,0-5 \%$ stained; $1,6-25 \%$ stained; 2, $26-50 \%$ stained; $3,51-75 \%$ stained; $4,76-100 \%$ stained. Finally, the IRS was defined as follows: 0-4; low expression; 5-12, high expression [24].

\section{Quantitative real-time PCR(RT-qPCR)}

Total RNA was extracted from fresh frozen tissue by using TRIzol reagent (Vazyme R401-01-AA, Nanjing, China), and reverse transcriptions were carried out with a PrimeScript RT reagent Kit (Vazyme R223-01, Nanjing, China). Gene-specific primers of human syntenin and $\beta$-actin were synthesized at Sangon Biotech (Shanghai) Co., Ltd. The primer sequences were as follows: human syntenin (forward primer, $5^{\prime}$ - TTCTGCTCCT ATCCCTCACG - 3' and reverse primer, 5' - CCAGTT ACAGGAGCCACCAT - 3'), $\beta$-actin (forward primer, 5' - ATCATGTTTGAGACCTTCAACACCCCAGCC $3^{\prime}$ and 5' $^{\prime}$ AAGAGAGCCTCGGGGCATCGGAACCG CTCA - 3'). The iCycler and iQ real-time PCR instruments (LighCycler 480II Roche Group Switzerland) and
SYBR-Green PCR Master Mix (Vazyme Q711-00, Nanjing, China) were used qRT-PCR. The qRT-PCR conditions were as follows: $95^{\circ} \mathrm{C}$ for $5 \mathrm{~min}$; and $95^{\circ} \mathrm{C}$ for $30 \mathrm{~s}$, $60{ }^{\circ} \mathrm{C}$ for $30 \mathrm{~s}$, and $72{ }^{\circ} \mathrm{C}$ for $30 \mathrm{~s}$ for 39 additional cycles. All experiments were repeated three times, and the mRNA levels were normalized to that of $\beta$-actin as an internal control.

\section{Enzyme-linked immunosorbent assay (ELISA)}

ELISA was conducted according to the instructions in the ELISA kit (Cloud-Clone, Houston, USA). $100 \mu \mathrm{L}$ of serum or standard product was added to the microplate and incubated at $37^{\circ} \mathrm{C}$ for $1 \mathrm{~h}$. The liquid was discarded, and the biotinylated antibody was added and incubated at $37^{\circ} \mathrm{C}$ for $1 \mathrm{~h}$. After washing, HRP-labelled antibody was added and incubated at $37^{\circ} \mathrm{C}$ for $30 \mathrm{~min}$. After thorough washing, the TMB substrates were added for 20 min at $37^{\circ} \mathrm{C}$ in the dark, and dilute sulfuric acid was added to terminate the reaction. The absorbance (A) value was measured at a wavelength of $450 \mathrm{~nm}$ on an ELISA instrument (Bio-Rad, California, USA). All samples were repeated three times, and the investigators were blinded to the clinical information.

\section{Statistical analysis}

Statistical analyses were performed using SPSS 23.0 software (SPSS Statistics, IBM, USA). The TNM stage of lung cancer was determined based on the eighth international lung cancer staging standards developed by the International Association for the Study of Lung Cancer. Kaplan-Meier analysis was applied to analyse the survival and prognosis of patient, and univariate and multivariate Cox proportional hazard regression analyses were used for survival-related variable analysis. The Wilcoxon signed-rank test was applied to examine the significance of differences in syntenin mRNA expression between the lung cancer tissue and paracancerous tissue. Spearman correlation analysis was applied to analyse the correlation between the expression of syntenin and VEGF in serum from patients with lung cancer. The expression of syntenin and VEGF in serum was represented as the median (quartile range) [M(P25 P75)]. The Mann-Whitney $\mathrm{U}$ test was used to compare continuous variables, and Pearson chi square test was used to compare categorical variables. A value of $P<0.05$ was considered statistically significant.

\section{Results}

\section{Syntenin was expressed in lung cancer tissues}

Syntenin expression was localized mostly to the cytoplasm in syntenin-expressing cancer. Of the 191 lung cancer cases, 93 were found to have high expression of syntenin (Table 1), and 98 cases had low expression of syntenin. The overall number of lung cancer samples 
Table 1 Expression of Syntenin in different pathological types of lung cancer

\begin{tabular}{llll}
\hline Pathologic types & Number of sample & Positive expression (\%) & Negative expression (\%) \\
\hline SSC & 49 & $20(40.8)$ & $29(59.2)$ \\
Adenocarcinoma & 119 & $61(51.3)$ & $58(48.7)$ \\
LCLC $^{\text {a }}$ & 2 & $0(0)$ & $2(100)$ \\
SCLC & 21 & $12(57.1)$ & $9(42.9)$ \\
Total & 191 & $93(48.7)$ & $98(51.3)$
\end{tabular}

SSC Squamous cell carcinoma, LCLC large cell lung cancer, SCLC small cell lung cancer. ${ }^{a}$ : LCLC was not compared with other types of lung cancer by chi-square test

with high syntenin expression was $48.7 \%$. However, all 80 cases of paracancerous normal lung tissue were low for expression of syntenin (Fig. 1a). RT-qPCR analysis showed that the expression of syntenin mRNA was significantly higher in lung cancer tissues than in paracancerous normal lung tissues $(P=0.008)$ (Fig. 2a). The expression of syntenin was detected in non-small cell lung cancer (NSCLC) and small cell lung cancer (SCLC); the proportion of highly-expressing samples for SCLC $(57.1 \%, 12 / 21)$ (Fig. 1c and d) was higher than that for adenocarcinoma (51.3\%, 61/119) (Fig. 1e and f) and for SSC (squamous cell carcinoma) $(40.8 \%, 20 / 49)$ (Fig. $1 \mathrm{~g}$ and $h$ ), whereas there was no statistically significant difference in syntenin expression among SCLC, adenocarcinoma and SSC $(P=0.348)$. There were only two cases of LCLC (large cell lung cancer) (Fig. 1b) in the study, and the expression of syntenin was low in both.

\section{Syntenin expression was associated with tumour size, TNM stage and distant metastasis}

Among the 191 cases of lung cancer, the high expression rate for syntenin was $57.0 \%$ in 121 cases where the diameter of tumours was greater than $3 \mathrm{~cm}$, while the high expression rate was $34.3 \%$ in 70 cases where the diameter of tumours was less than or equal to $3 \mathrm{~cm}$, and the difference was statistically significant $(P=0.002)$. The high expression rate of syntenin in 111 cases with stage III and IV lung cancer was $55.9 \%$, and the rate in 80 cases with stage I and II lung cancer was $38.8 \%$, with a statistically significant difference $(P=0.020)$. Among the 58 cases of lung cancer with distant metastasis, the rate of high syntenin expression was $60.3 \%$, while among the 133 cases of lung cancer without distant metastasis, only 58 cases were highly expressed (the rate was $43.6 \%$ ), and the difference was statistically significant
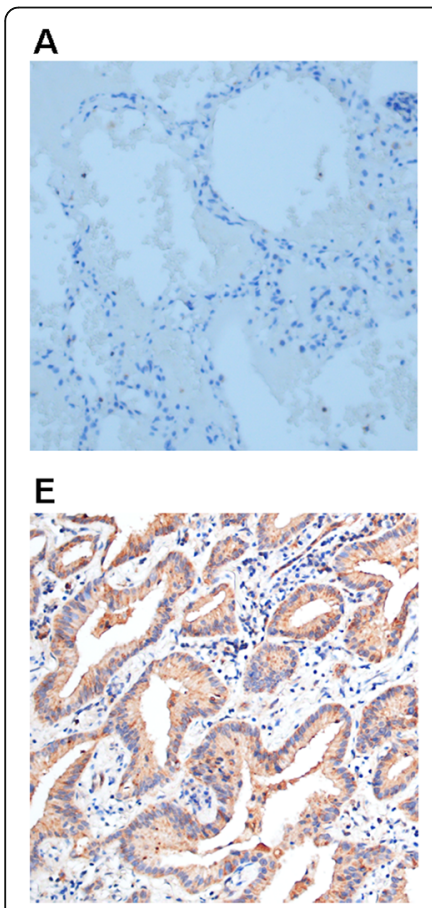

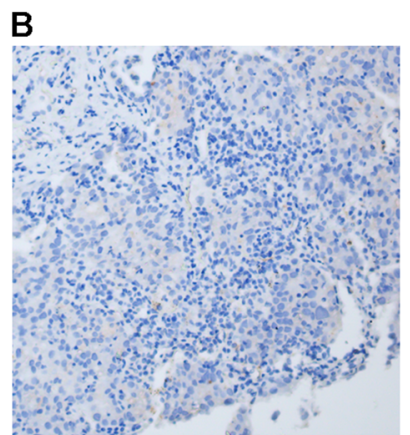

$\mathbf{F}$

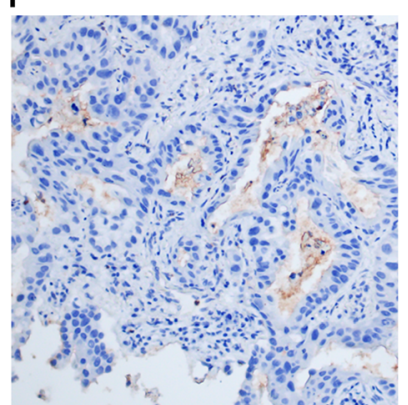

C

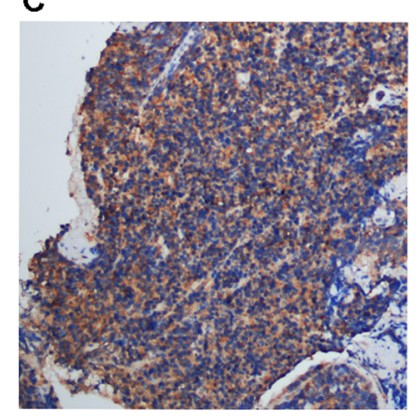

G

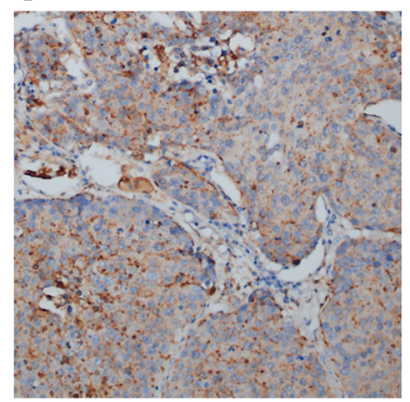

D

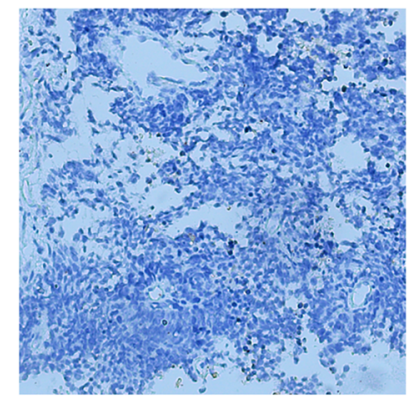

H

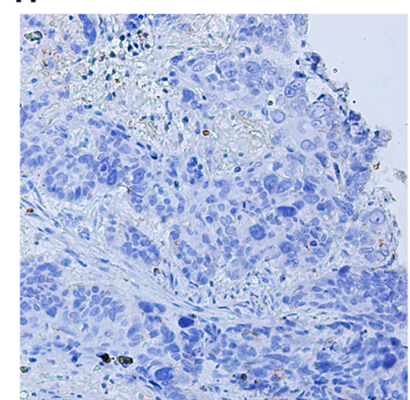

Fig. 1 Syntenin expression in lung cancer tissue and lung tissue as detected by immunohistochemistry. The low expression of syntenin in lung tissue (a) and large cell lung cancer (b); the high and low expression of syntenin in small cell lung cancer (c, $\mathbf{d})$. The high and low expression of syntenin in adenocarcinoma (e, f); the high and low expression of syntenin in squamous cell carcinoma $(\mathbf{g}, \mathbf{h})$. Original magnification, $\times 200$ 

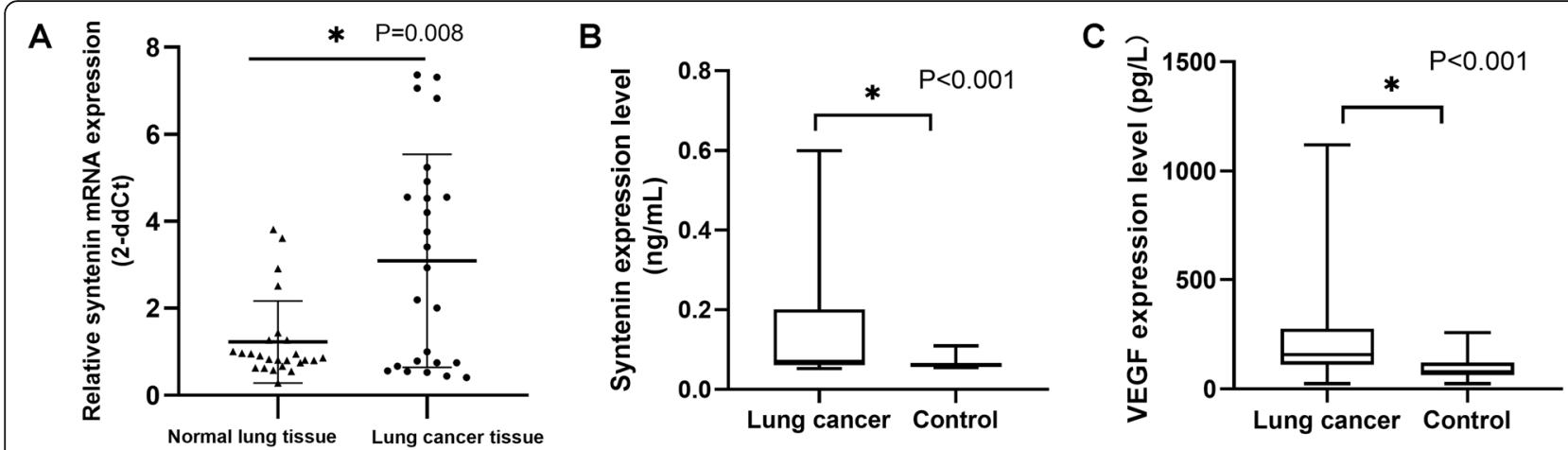

Fig. 2 RT-qPCR analysis showed that the mRNA expression of syntenin in fresh lung cancer tissue was significantly higher than that in adjacent noncancerous tissues $(P=0.008)(\mathbf{a})$. ELISA showed that the expression level of syntenin and VEGF in serum of lung cancer patients was significantly higher than that of control group $(P<0.001, P<0.001$ respectively) $(\mathbf{b}, \mathbf{c})$

$(P=0.033)$. The expression of syntenin was independent of lymph node status, age, sex and performance status $(P>0.05)$ (Table 2).

\section{Syntenin expression was associated with shorter OS and PFS}

Kaplan-Meier survival analysis showed that the OS $(P=$ $0.002)$ and PFS $(P=0.001)$ of the lung cancer patients with high syntenin expression were significantly shorter than those of patients with low syntenin expression, and there was a statistically significant difference between high and low groups (Fig. 3 a and b). We further analysed lung cancer patients receiving surgery and chemotherapy separately, and the results showed that the OS $(P=0.006)$ and PFS $(P=0.004)$ of lung cancer patients with high syntenin expression were significantly shorter than those with low syntenin expression in 80 surgically treated patients (Fig. 3c and d). In addition, among the 111 patients treated with chemotherapy, the OS $(P=$ $0.019)$ and PFS $(P<0.001)$ of patients with high syntenin expression were significantly shorter than those with low syntenin expression (Fig. 3e and f). To further explore the influence of different chemotherapy treatments on the prognosis of patients, Kaplan Meier survival analysis was performed and the results showed that OS and PFS in EGFR-TKI treatment group were longer than those in platinum chemotherapy group, and OS and PFS in platinum chemotherapy group were significantly longer than those in palliative treatment group $(P<0.001, P<0.001$, respectively) (Fig. $3 g$ and $h$ ).

\section{Factors affecting prognosis of lung cancer}

Univariate COX proportional hazard regression analysis indicate that tumour size $(P=0.01$ and 0.007 for OS and PFS, respectively), distant metastasis $(P<0.001$ for OS and PFS), lymph node metastasis $(P<0.001$ for OS and $P$ PFS), performance status $(P<0.001$ for OS and PFS $)$ and syntenin expression $(P=0.004$ and $=0.001$ for $\mathrm{OS}$ and PFS, respectively) were factors predicting a poor prognosis in lung cancer patients. Unsurprisingly, surgical treatment $(P<0.001$ for OS and PFS) indicated good prognosis in the patients. Moreover, multivariate COX proportional hazard regression analysis demonstrated

Table 2 Syntenin expression in relation to clinical parameters and pathological characteristics

\begin{tabular}{|c|c|c|c|c|}
\hline \multirow[t]{2}{*}{ Variable } & \multirow{2}{*}{$\begin{array}{l}\text { Number } \\
\text { of } \\
\text { sample }\end{array}$} & \multicolumn{2}{|l|}{ Syntenin } & \multirow[t]{2}{*}{$P$} \\
\hline & & \multicolumn{2}{|c|}{ high (\%) low (\%) } & \\
\hline \multicolumn{5}{|l|}{ Tumor size $(\mathrm{cm})$} \\
\hline$\leq 3$ & 70 & $24(34.3)$ & $46(65.7)$ & 0.002 \\
\hline$>3$ & 121 & $69(57.0)$ & $52(43.0)$ & \\
\hline \multicolumn{5}{|l|}{ TNM stage } \\
\hline$I+\|$ & 80 & $31(38.8)$ & $49(61.2)$ & 0.020 \\
\hline$I I I+I V$ & 111 & $62(55.9)$ & $49(44.1)$ & \\
\hline \multicolumn{5}{|l|}{ Distant metastasis } \\
\hline Negative & 133 & $58(43.6)$ & $75(56.4)$ & 0.033 \\
\hline Positive & 58 & $35(60.3)$ & $23(39.7)$ & \\
\hline \multicolumn{5}{|l|}{ Lymphnode } \\
\hline \multicolumn{5}{|l|}{ metastasis } \\
\hline Negative & 91 & $38(41.8)$ & $53(58.2)$ & 0.067 \\
\hline Positive & 100 & $55(55.0)$ & $45(45.0)$ & \\
\hline \multicolumn{5}{|l|}{ Sex } \\
\hline Men & 140 & 68 (48.6) & $72(51.4)$ & 0.956 \\
\hline Women & 51 & $25(49.0)$ & $26(51.0)$ & \\
\hline \multicolumn{5}{|l|}{ Age (years) } \\
\hline$\leq 60$ & 84 & $39(46.4)$ & $45(53.6)$ & 0.579 \\
\hline$>60$ & 107 & $54(50.5)$ & $53(49.5)$ & \\
\hline Performance status & & & & 0.961 \\
\hline$\leq 2$ & 162 & $79(50.1)$ & $83(53.5)$ & \\
\hline$>2$ & 29 & $14(48.3)$ & $15(51.7)$ & \\
\hline
\end{tabular}

$P$ value is the result of chi-square test, and the expression level of syntenin is significantly correlated with tumor size, TNM stage and distant metastasis of tumor 


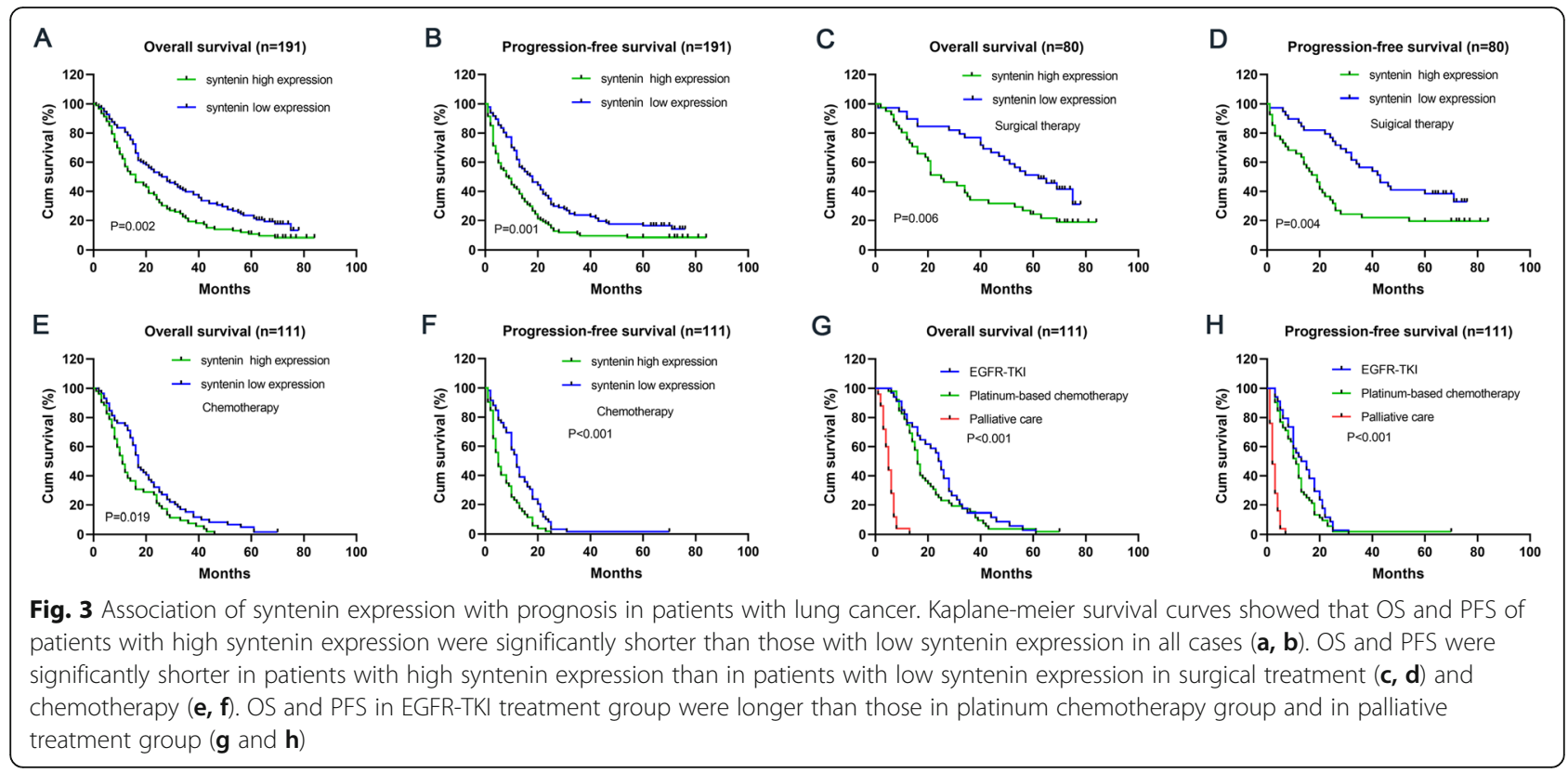

that distant metastasis $(P<0.001$ for OS and PFS), lymph node metastasis $(P=0.005$ and $=0.004$ for OS and PFS, respectively), syntenin expression $(P=0.006$ and $<0.001$ for OS and PFS, respectively) and performance status $(\mathrm{P}<0.001$ for $\mathrm{OS}$ and PFS) were independent risk factors for poor prognosis. In addition, we showed that surgical treatment $(P<0.001$ for OS and PFS) was an independent protective factor for the patients, and SCLC had even worse prognosis than NSCLC $(P=0.047)$ (Tables 3 and 4). Histological types were related to OS, but not PFS, which might be due to small number of SCLC cases in the study.

\section{Expression of syntenin in serum from patients with lung cancer and its relationship with VEGF expression}

In the cancer group, 55 patients had NSCLC, and five patients had SCLC. The expression level of syntenin in the serum from lung cancer group was significantly higher than from the control group $(P<0.001)(0.071$ vs $0.061 \mathrm{ng} / \mathrm{mL}$ ). The VEGF level in serum from the lung cancer group was significantly higher than that from the control group $(P<0.001) \quad(158.479$ vs $78.612 \mathrm{pg} / \mathrm{mL})$. Spearman correlation analysis showed that the syntenin and VEGF levels were positively correlated (correlation coefficient $=0.49, P<0.001$ ). However, further analysis revealed no significant correlation between the syntenin and VEGF levels in serum of the control subjects (correlation coefficient $=0.257, P=0.171$ ). The serum syntenin and VEGF levels in lung cancer patients and control subjects are shown in Fig. $2 \mathrm{~b}$ and $\mathrm{c}$ and the correlation analysis of serum syntenin and VEGF levels in lung cancer patients and control subjects is shown in Table 5.

\section{Discussion}

Syntenin is highly expressed in the metastatic tumour cells when compared with non-metastatic tumour cells

Table 3 Univariate and multivariate COX regression analysis of prognostic factors in lung cancer patients for OS

\begin{tabular}{|c|c|c|c|c|c|c|}
\hline \multirow[t]{2}{*}{ Variable } & \multicolumn{3}{|c|}{ Univariate analysis } & \multicolumn{3}{|c|}{ Multivariate analysis } \\
\hline & Hazard ratio & $95 \% \mathrm{Cl}$ & $P$ & Hazard ratio & $95 \% \mathrm{Cl}$ & $P$ \\
\hline Tumor size & 1.524 & $1.104 \sim 2.103$ & 0.01 & 1.319 & $0.932 \sim 1.867$ & 0.118 \\
\hline Distant metastases & 4.786 & $3.331 \sim 6.877$ & $<0.001$ & 2.893 & $1.916 \sim 4.370$ & $<0.001$ \\
\hline Lymph node metastasis & 2.102 & $1.537 \sim 2.877$ & $<0.001$ & 1.604 & $1.156 \sim 2.227$ & 0.005 \\
\hline Sugical treatment & 0.274 & $0.193 \sim 0.390$ & $<0.001$ & 0.489 & $0.320 \sim 0.749$ & 0.001 \\
\hline Age & 1.063 & $0.782 \sim 1.445$ & 0.698 & & & \\
\hline Sex & 0.796 & $0.559 \sim 1.135$ & 0.207 & & & \\
\hline Syntenin expression & 1.572 & $1.157 \sim 2.136$ & 0.004 & 1.580 & $1.141 \sim 2.188$ & 0.006 \\
\hline Performance status & 8.903 & $5.700 \sim 13.907$ & $<0.001$ & 6.371 & $3.750 \sim 10.822$ & $<0.001$ \\
\hline Histology & 0.595 & $0.367 \sim 0.964$ & 0.035 & 0.600 & $0.362 \sim 0.994$ & 0.047 \\
\hline
\end{tabular}


Table 4 Univariate and multivariate COX regression analysis of prognostic factors in lung cancer patients for PFS

\begin{tabular}{|c|c|c|c|c|c|c|}
\hline \multirow[t]{2}{*}{ Variable } & \multicolumn{3}{|c|}{ Univariate analysis } & \multicolumn{3}{|c|}{ Multivariate analysis } \\
\hline & Hazard ratio & $95 \% \mathrm{Cl}$ & $P$ & Hazard ratio & $95 \% \mathrm{Cl}$ & $P$ \\
\hline Tumor size & 1.557 & $1.130 \sim 2.144$ & 0.007 & 1.162 & $0.830 \sim 1.627$ & 0.383 \\
\hline Distant metastasis & 5.754 & $3.888 \sim 8.515$ & $<0.001$ & 2.773 & $1.816 \sim 4.236$ & $<0.001$ \\
\hline Lymph node metastasis & 2.155 & $1.575 \sim 2.950$ & $<0.001$ & 1.613 & $1.165 \sim 2.234$ & 0.004 \\
\hline Sugical treatment & 0.245 & $0.169 \sim 0.353$ & $<0.001$ & 0.338 & $0.219 \sim 0.522$ & $<0.001$ \\
\hline Age & 1.034 & $0.762 \sim 1.402$ & 0.831 & & & \\
\hline Sex & 0.767 & $0.540 \sim 1.091$ & 0.140 & & & \\
\hline Syntenin expression & 1.689 & $1.245 \sim 2.291$ & 0.001 & 1.889 & $1.369 \sim 2.607$ & $<0.001$ \\
\hline Performance status & 7.578 & $4.778 \sim 12.020$ & $<0.001$ & 4.309 & $2.603 \sim 7.131$ & $<0.001$ \\
\hline Histology & 0.640 & $0.395 \sim 1.035$ & 0.069 & & & \\
\hline
\end{tabular}

Distant metastasis $(P<0.001)$, lymph node metastasis $(P=0.001)$, syntenin expression

and normal cells, and is suggested to cause metastasis by regulating the transportation of tumour cells [11, 15], resulting in poor prognosis in patients. However, the role of syntenin in the occurrence and development of lung cancer is largely unknown. Therefore, we investigated the expression of syntenin in human lung cancer tissues and serum in patients with lung cancer and the relationship between syntenin expression and clinicopathology. Our study shows that the syntenin level in the cancer tissue is significantly higher than in paracancerous lung tissue. Northern blot analysis in previous studies indicated that syntenin mRNA is abundant in adult heart and placental tissues but very low in lung tissues [25]. In addition, we found that elevated syntenin expression was correlated with tumour size, TNM stage and distant metastasis, suggesting that syntenin is involved in the occurrence and development of tumours. In breast cancer the overexpression of syntenin is found to be correlated with tumour size, lymph node status, the OS rate, and the PFS rate [15]. Kaplan-Meier analysis further suggested that the OS and PFS in high syntenin patients are significantly shorter than those in low patients. This is consistent with previous results that the abnormal expression of syntenin is related to poor clinical prognosis in glioma, breast cancer, uveal melanoma and lung adenocarcinoma [11, 15, 26, 27]. At the same time, Kaplan Meier analysis showed that the prognosis of patients treated with EGFR-TKI gefitinib is better than that of patients treated with platinum chemotherapy and palliative treatment. Previous studies show that gefitinib has significant clinical efficacy in the first-line treatment of advanced NSCLC patients [28] and the prognosis of patients with platinum chemotherapy is better than that of patients with palliative treatment. However, if the patients have high PS score, their prognosis with palliative treatment is poor. Syntenin was believed to promote the invasion and migration of various tumor cells through the integrin signaling pathway, but recent studies have shown that syntenin also promotes the invasion and migration of tumor cells without the induction of cell matrix [11, 29, 30]. Nevertheless, it is clear that elevated syntenin expression may play a vital role in the development of lung cancer.

Currently, the assessment of lung cancer prognosis relies on TNM staging. However, TNM staging is not always able to predict the prognosis of patients, and there is an urgent need for other clinical prognostic markers to assist and supplement TNM staging. Moreover, identifying novel biomarkers that predict the prognosis of lung cancer patients is helpful for the selection of treatment regimens and the improvement of survival rate. This study showed that the overexpression of syntenin in lung cancer tissues is correlated with poor prognosis in lung cancer. Univariate and multivariable COX proportional hazard regression analyses further showed that the overexpression syntenin is an independent risk factor for lung cancer patients with poor prognosis. Therefore, syntenin may be used as a new prognostic marker for lung cancer.

At present, VEGF has been widely recognized to play an indispensable role in angiogenesis during tumour growth [31], and VEGF levels in serum from lung cancer patients have also been measured in previous studies. However, there is no studies that report the level of

Table 5 Correlation analysis of serum syntenin and VEGF levels in lung cancer patients and control subjects

\begin{tabular}{lllll}
\hline Group & Syntenin $(\mathrm{ng} / \mathrm{mL})$ & VEGF $(\mathrm{pg} / \mathrm{mL})$ & $r$ & \\
\hline Lung cancer & $0.071(0.062 \sim 0.200)$ & $158.479(112.491 \sim 276.235)$ & 0.49 & $<0.001$ \\
Control & $0.061(0.058 \sim 0.067)$ & $78.612(64.824 \sim 121.209)$ & 0.257 & 0.171 \\
\hline
\end{tabular}


syntenin in serum from lung cancer patients. In this study, we found that the serum level of syntenin in lung cancer patients is significantly higher than that in control subjects, which may be related to the high tumor burden of lung cancer patients. We also confirmed that the level of serum VEGF is higher from lung cancer patients than from control subjects as found previously for NSCLC [32]. In addition, we further found that there is a positive correlation between serum syntenin and VEGF levels in patients with lung cancer, suggesting that the increased expression of VEGF may be related to the overexpression of syntenin. Since the effect of syntenin on VEGF downstream pathway may be different in different pathological types of lung cancer, our study did not further investigate how syntenin mediates the increase of VEGF expression in lung cancer patients. With the gradual increase of tumor volume, hypoxia appears, resulting in increased expression of hypoxia-inducible factor-1 $\alpha$ (HIF-1 $\alpha$ ) and VEGF to promote angiogenesis in tumor. It has been shown that the overexpression of HIF- $1 \alpha$ in lung cancer can regulate VEGF transcription and neovascularization in a positive feedback way. Therefore, the increase of HIF-1 $\alpha$ reflects the occurrence and progress of cancer [33]. HIF-1 $\alpha$ and VEGF overexpressed in lung cancer are secreted into the blood and can be used to diagnose the cancer [34], Syntenin is shown to inhibit apoptosis [35] and inhibition of syntenin will reduce the activity of VEGF [19]. In melanoma, syntenin induces angiogenesis by activating Akt, leading to the expression of HIF- $1 \alpha$ and the transcription of IGF-binding protein-2 (IGFBP-2), which induces the production of VEGF in endothelial cells and angiogenesis [36]. In addition, the inhibition of syntenin protein expression reduces microvascular branching in vivo and the number of tumour vessels in an orthotopic xenograft mouse model [11]. Studies have shown that syntenin is abnormally expressed in pulmonary and hepatic veins during mouse embryonic development, indicating that it plays an important role in regulating the function of endothelial cells [37]. All of the above studies indicate that syntenin can promote angiogenesis in tumour through different molecular pathways.

This study was a combination of retrospective and prospective studies. The patients experienced different anticancer treatments and had different levels of tumour progression, adverse reactions to anticancer treatment, and nutritional statuses; all of these factors have not been taken into account. The entire study population was from the Haikou Hospital, and almost all the patients were from Hainan Province, which had certain bias and limitations.

\section{Conclusion}

Our work has demonstrated that syntenin expression is increased in lung cancer tissues and serum of lung cancer patients, and overexpression of syntenin is significantly correlated with poor prognosis of lung cancer patients. Combined with previous studies, it is clear that syntenin plays an important role in regulating metastasis and angiogenesis in lung cancer. Therefore, syntenin is expected to become a new diagnostic and prognostic marker for lung cancer, and syntenin-targeted therapy is expected to be a new supplement to traditional treatment methods. Due to the limitations described above, further study is needed to investigate the role of syntenin in lung cancer at molecular and cellular levels to develop targeted therapy.

\section{Abbreviations}

A: Absorbance; COPD: Chronic obstructive pulmonary disease; ELISA: Enzyme-linked immunosorbent assay; IRS: Immunoreactive score; LCLC: Large cell lung cancer; MDA-9: Melanoma differentiation-associated gene-9 (MDA-9); NSCLC: Non-small cell lung cancer; OS: Overall survival; PFS: Progression-free survival; PP: Percentage of positive cells; PS: Performance status; RT-qPCR: Quantitative real-time polymerase chain reaction; SCLC: Small cell lung cancer; SI: Staining intensity; SSC: Squamous cell carcinoma; VEGF: Vascular endothelial growth factor; VEGFR: Vascular endothelial growth factor receptor

\section{Acknowledgements}

We thank the pathologists, Professor Shun Tan and Deputy Chief Physician Xiang Rao (Haikou Hospital, affiliated with Central South University, Haikou, China), for evaluating the immunostaining results.

\section{Authors' contributions}

$\mathrm{ZO}$ provided the concept, PL and XY designed the experiments. PL performed the immunohistochemical and ELISA experiments. XY and SH analysed the data, SF and ZO drafted the manuscript and all the authors read and approved the final manuscript.

\section{Funding}

No specific funding was received.

\section{Availability of data and materials}

The datasets used during the current study are available from the corresponding author on reasonable request.

\section{Ethics approval and consent to participate}

This study was approved by the Ethics Committee of Haikou Hospital affiliated with the Xiangya School of Medicine (the approval number is 2017-145), and was performed in accordance with the ethical standards laid down in the 1964 Declaration of Helsinki and its later amendments. Written consent was obtained from all patients.

\section{Consent for publication}

Not Applicable.

\section{Competing interests}

The authors declare that they have no competing interests.

Received: 24 October 2019 Accepted: 31 January 2020

Published online: 27 February 2020

\section{References}

1. Bray F, Ferlay J, Soerjomataram I, Siegel RL, Torre LA, Jemal A. Global cancer statistics 2018: GLOBOCAN estimates of incidence and mortality worldwide for 36 cancers in 185 countries. CA Cancer J Clin. 2018;68(6):394-424.

2. Hoffman PC, Mauer AM, Vokes EE. Lung cancer. Lancet. 2000;355(9202):47985.

3. Miller YE. Pathogenesis of lung cancer: 100 year report. Am J Respir Cell Mol Biol. 2005;33(3):216-23.

4. Chu BF, Otterson GA. Incorporation of Antiangiogenic therapy into the nonsmall-cell lung Cancer paradigm. Clin Lung Cancer. 2016;17(6):493-506. 
5. Bunn PA Jr. Karnofsky award 2016: a lung Cancer journey, 1973 to 2016. J Clin Oncol. 2017;35(2):243-52.

6. Damaraju VL, Kuzma M, Mowles D, Cass CE, Sawyer MB. Interactions of multitargeted kinase inhibitors and nucleoside drugs: Achilles heel of combination therapy? Mol Cancer Ther. 2015;14(1):236-45.

7. Moserle L, Jimenez-Valerio G, Casanovas O. Antiangiogenic therapies: going beyond their limits. Cancer Discov. 2014;4(1):31-41.

8. Liu J, Qu J, Zhou W, Huang Y, Jia L, Huang X, Qian Z, Xia J, Yu Y. Syntenintargeted peptide blocker inhibits progression of cancer cells. Eur J Med Chem. 2018;154:354-66.

9. Kegelman TP, Wu B, Das SK, Talukdar S, Beckta JM, Hu B, Emdad L, Valerie K, Sarkar D, Furnari FB, et al. Inhibition of radiation-induced glioblastoma invasion by genetic and pharmacological targeting of MDA-9/Syntenin. Proc Natl Acad Sci U S A. 2017;114(2):370-5.

10. Kegelman TP, Das SK, Emdad L, Hu B, Menezes ME, Bhoopathi P, Wang XY, Pellecchia M, Sarkar D, Fisher PB. Targeting tumor invasion: the roles of MDA-9/Syntenin. Expert Opin Ther Targets. 2015;19(1):97-112.

11. Kegelman TP, Das SK, Hu B, Bacolod MD, Fuller CE, Menezes ME, Emdad L, Dasgupta $\mathrm{S}$, Baldwin AS, Bruce JN, et al. MDA-9/syntenin is a key regulator of glioma pathogenesis. Neuro-Oncology. 2014;16(1):50-61.

12. Das SK, Bhutia SK, Kegelman TP, Peachy L, Oyesanya RA, Dasgupta S, Sokhi UK, Azab B, Dash R, Quinn BA, et al. MDA-9/syntenin: a positive gatekeeper of melanoma metastasis. Front Biosci (Landmark Ed). 2012;17:1-15.

13. Kim WY, Jang JY, Jeon YK, Chung DH, Kim YG, Kim CW. Syntenin increases the invasiveness of small cell lung cancer cells by activating p38, AKT, focal adhesion kinase and SP1. Exp Mol Med. 2014;46:e90.

14. Liu X, Zhang X, Lv Y, Xiang J, Shi J. Overexpression of syntenin enhances hepatoma cell proliferation and invasion: potential roles in human hepatoma. Oncol Rep. 2014;32(6):2810-6.

15. Yang Y, Hong Q, Shi P, Liu Z, Luo J, Shao Z. Elevated expression of syntenin in breast cancer is correlated with lymph node metastasis and poor patient survival. Breast Cancer Res. 2013;15(3):R50.

16. Hirbec $\mathrm{H}$, Martin S, Henley JM. Syntenin is involved in the developmental regulation of neuronal membrane architecture. Mol Cell Neurosci. 2005; 28(4):737-46.

17. Meerschaert K, Bruyneel E, De Wever O, Vanloo B, Boucherie C, Bracke M, Vandekerckhove J, Gettemans J. The tandem PDZ domains of syntenin promote cell invasion. Exp Cell Res. 2007;313(9):1790-804.

18. Sarkar D, Boukerche H, Su ZZ, Fisher PB. mda-9/syntenin: recent insights into a novel cell signaling and metastasis-associated gene. Pharmacol Ther. 2004;104(2):101-15.

19. Tae N, Lee S, Kim O, Park J, Na S, Lee JH. Syntenin promotes VEGF-induced VEGFR2 endocytosis and angiogenesis by increasing ephrin-B2 function in endothelial cells. Oncotarget. 2017;8(24):38886-901.

20. Delli Carpini J, Karam AK, Montgomery L. Vascular endothelial growth factor and its relationship to the prognosis and treatment of breast, ovarian, and cervical cancer. Angiogenesis. 2010;13(1):43-58.

21. Li YL, Zhao H, Ren XB. Relationship of VEGFNEGFR with immune and cancer cells: staggering or forward? Cancer Biol Med. 2016;13(2):206-14.

22. Chow S, Shao J, Wang H. Sample size calculations in clinical research, vol. New York: Chapman and Hall; 2008.

23. Friedrichs K, Gluba S, Eidtmann H, Jonat W. Overexpression of p53 and prognosis in breast cancer. Cancer. 1993;72(12):3641-7.

24. Li M, Xiao T, Zhang Y, Feng L, Lin D, Liu Y, Mao Y, Guo S, Han N, Di X, et al. Prognostic significance of matrix metalloproteinase-1 levels in peripheral plasma and tumour tissues of lung cancer patients. Lung Cancer. 2010;69(3): 341-7.

25. Zimmermann P, Tomatis D, Rosas M, Grootjans J, Leenaerts I, Degeest G, Reekmans G, Coomans C, David G. Characterization of syntenin, a syndecanbinding PDZ protein, as a component of cell adhesion sites and microfilaments. Mol Biol Cell. 2001;12(2):339-50.

26. Wang LK, Pan SH, Chang YL, Hung PF, Kao SH, Wang WL, Lin CW, Yang SC, Liang $\mathrm{CH}$, Wu $\mathrm{CT}$, et al. MDA-9/Syntenin-slug transcriptional complex promote epithelial-mesenchymal transition and invasion/metastasis in lung adenocarcinoma. Oncotarget. 2016;7(1):386-401.

27. Gangemi R, Mirisola V, Barisione G, Fabbi M, Brizzolara A, Lanza F, Mosci C, Salvi S, Gualco M, Truini M, et al. Mda-9/syntenin is expressed in uveal melanoma and correlates with metastatic progression. PLoS One. 2012;7(1): e29989.

28. Fukuoka M, Wu YL, Thongprasert S, Sunpaweravong P, Leong SS, Sriuranpong V, Chao TY, Nakagawa K, Chu DT, Saijo N, et al. Biomarker analyses and final overall survival results from a phase III, randomized, openlabel, first-line study of gefitinib versus carboplatin/paclitaxel in clinically selected patients with advanced non-small-cell lung cancer in Asia (IPASS). J Clin Oncol. 2011;29(21):2866-74.

29. Dasgupta S, Menezes ME, Das SK, Emdad L, Janjic A, Bhatia S, Mukhopadhyay ND, Shao C, Sarkar D, Fisher PB. Novel role of MDA-9/ syntenin in regulating urothelial cell proliferation by modulating EGFR signaling. Clin Cancer Res. 2013;19(17):4621-33.

30. Das SK, Pradhan AK, Bhoopathi P, Talukdar S, Shen XN, Sarkar D, Emdad L, Fisher PB. The MDA-9/Syntenin/IGF1R/STAT3 Axis directs prostate Cancer invasion. Cancer Res. 2018;78(11):2852-63.

31. Hicklin DJ, Ellis LM. Role of the vascular endothelial growth factor pathway in tumor growth and angiogenesis. J Clin Oncol. 2005;23(5):1011-27.

32. Liu SG, Yuan SH, Wu HY, Liu J, Huang CS. The clinical research of serum VEGF, TGF-beta1, and Endostatin in non-small cell lung Cancer. Cell Biochem Biophys. 2015;72(1):165-9.

33. Chen W, Sai W, Yang X, Cai Y, Gu J, Wang L, Wu W, Yao D. Clinical values on analysis of cancerous tissue or circulating hypoxia-inducible factor-1a expression levels in patients with lung cancer. J Mod Med Health. 2016; 32(6):804-7.

34. Sanmartin E, Sirera R, Uso M, Blasco A, Gallach S, Figueroa S, Martinez N, Hernando C, Honguero A, Martorell M, et al. A gene signature combining the tissue expression of three angiogenic factors is a prognostic marker in early-stage non-small cell lung cancer. Ann Surg Oncol. 2014;21 (2):612-20.

35. Talukdar S, Pradhan AK, Bhoopathi P, Shen XN, August LA, Windle JJ, Sarkar D, Furnari FB, Cavenee WK, Das SK, et al. MDA-9/Syntenin regulates protective autophagy in anoikis-resistant glioma stem cells. Proc Natl Acad Sci U S A. 2018;115(22):5768-73.

36. Das SK, Bhutia SK, Azab B, Kegelman TP, Peachy L, Santhekadur PK, Dasgupta S, Dash R, Dent P, Grant S, et al. MDA-9/syntenin and IGFBP-2 promote angiogenesis in human melanoma. Cancer Res. 2013;73(2):844-54.

37. Qian XL, Li YQ, Yu B, Gu F, Liu FF, Li WD, Zhang XM, Fu L. Syndecan binding protein (SDCBP) is overexpressed in estrogen receptor negative breast cancers, and is a potential promoter for tumor proliferation. PLoS One. 2013;8(3):e60046.

\section{Publisher's Note}

Springer Nature remains neutral with regard to jurisdictional claims in published maps and institutional affiliations.

Ready to submit your research? Choose BMC and benefit from

- fast, convenient online submission

- thorough peer review by experienced researchers in your field

- rapid publication on acceptance

- support for research data, including large and complex data types

- gold Open Access which fosters wider collaboration and increased citations

- maximum visibility for your research: over $100 \mathrm{M}$ website views per year

At BMC, research is always in progress.

Learn more biomedcentral.com/submissions 